\title{
Determinants of an elevated pulmonary arterial pressure in patients with pulmonary arterial hypertension
}

\author{
Seiichiro Sakao ${ }^{1 *}$, Norbert F. Voelkel ${ }^{2}$, Nobuhiro Tanabe ${ }^{1}$ and Koichiro Tatsumi ${ }^{1}$
}

\begin{abstract}
Given the difficulty of diagnosing early-stage pulmonary arterial hypertension (PAH) due to the lack of signs and symptoms, and the risk of an open lung biopsy, the precise pathological features of presymptomatic stage lung tissue remain unknown. It has been suggested that the maximum elevation of the mean pulmonary arterial pressure $\left(P_{\mathrm{pa}}\right)$ is achieved during the early symptomatic stage, indicating that the elevation of the mean $P_{\mathrm{pa}}$ is primarily driven by the pulmonary vascular tone and/or some degree of pulmonary vascular remodeling completed during this stage. Recently, the examination of a rat model of severe PAH suggested that the severe PAH may be primarily determined by the presence of intimal lesions and/or the vascular tone in the early stage. Human data seem to indicate that intimal lesions are essential for the severely increased pulmonary arterial blood pressure in the late stage of the disease.

However, many questions remain. For instance, how does the pulmonary hemodynamics change during the course of the disease, and what drives the development of severe PAH? Although it is generally acknowledged that both pulmonary vascular remodeling and the vascular tone are important determinants of an elevated pulmonary arterial pressure, which is the root cause of the time-dependent progression of the disease? Here we review the recent histopathological concepts of PAH with respect to the progression of the lung vascular disease.
\end{abstract}

Keywords: Pulmonary arterial hypertension (PAH), Pulmonary vascular remodeling, Heath-edwards classification

\section{Introduction}

Almost all of the previous large studies which have described the features of pulmonary vascular remodeling in patients with severe angioobliterative $\mathrm{PAH}$, including IPAH and PAH associated with congenital heart disease (CHD), have been based on autopsy samples obtained from patients with end stage PAH [1]. Given the difficulty of diagnosing early-stage PAH because of the lack of signs and symptoms [2-5], and because we lack open lung biopsies that are risky in patients with severe PAH, the pathological features of early lung vascular disease (during the presymptomatic stage) in patients with severe PAH remain unclear. Most likely severe angioobliterative $\mathrm{PAH}$ is not histologically homogeneous and the pathological grading method proposed by Heath and Edwards

\footnotetext{
*Correspondence: sakaos@faculty.chiba-u.jp

${ }^{1}$ Department of Respirology (B2), Graduate School of Medicine, Chiba

University, 1-8-1 Inohana, Chuo-ku, Chiba 260-8670, Japan

Full list of author information is available at the end of the article
}

to assess PAH is based largely on lung tissue samples from patients with CHD [6]. Heath and Edwards demonstrated that, among $\mathrm{PAH}$ patients with $\mathrm{CHD}$, the medial thickness of the muscular pulmonary arteries and muscularization of the pulmonary arterioles without intimal alterations (grade 1) are the earliest abnormalities of the pulmonary vasculature. These patients were subjected to high systemic blood pressure from birth due to congenital cardiac anomalies. Moreover, they showed that, together with the medial hypertrophy, intimal thickness with cell proliferation in the smaller muscular pulmonary arteries (grade 2), intimal obstruction with concentric or eccentric masses of less cellular fibrous tissue (grade 3) and progressive (grade 4) and chronic (grade 5) dilation of the small arteries with plexiform and angiomatoid lesions, appear as a result of an elevated 
blood pressure in the pulmonary arteries due to CHD [6] (Table 1). Although never supported by evidences, it is generally believed that these pathological alterations gradually progress over time from grade 1 to 5 [6].

It has also been suggested that the maximum elevation of the mean pulmonary arterial pressure $\left(P_{\mathrm{pa}}\right)$ in $\mathrm{PAH}$ patients is achieved during the early symptomatic stage $[2,4]$, indicating that the elevation of the mean $P_{\mathrm{pa}}$ is driven by the pulmonary vascular tone and/or the degree of pulmonary vascular remodeling completed during this stage. The relative contribution of vasoconstriction to the mean $P_{\mathrm{pa}}$ varies between patients [7] and is perhaps larger during the presymptomatic phase of PAH due to the progression of pulmonary vascular remodeling in a time-dependent manner [6].

Recently, in a rat model of severe PAH it has been shown that the elevated pulmonary arterial pressure appears to be primarily driven by grade 1 and 2 remodeling (according to the Heath-Edwards classification) and/or the vascular tone. Complex vascular lesions, including those of Heath-Edwards grade 4, may develop as a consequence of the high pulmonary arterial pressure or shear stress $[8,9]$.

Here we review the recent histopathological concepts of PAH with respect to the stage of disease progression, guided by the questions: how does pulmonary hemodynamics change during the course of the disease and what degree of pulmonary vascular remodeling increases the $P_{\mathrm{pa}}$ ? We first mention the recent pathophysiological findings in a rodent model of severe $\mathrm{PAH}$ and then the histopathological features in patients with PAH who had been treated with the currently available PAHtargeted drugs. Subsequently, we consider the determinants of the elevated pulmonary arterial pressure from these findings and the therapeutic strategies in accordance with different disease stages.

Table 1 The Heath and Edwards pathological grading method

\begin{tabular}{|c|c|}
\hline & tenially Reversable \\
\hline 1 & $\begin{array}{l}\text { The medial thickness of the muscular pulmonary arteries and } \\
\text { muscularization of the pulmonary arterioles without intimal } \\
\text { alterations. }\end{array}$ \\
\hline 2 & $\begin{array}{l}\text { Together with the medial hypertrophy, intimal thickness with cell } \\
\text { proliferation in the smaller muscular pulmonary arteries. }\end{array}$ \\
\hline 3 & $\begin{array}{l}\text { Intimal obstruction with concentric or eccentric masses of less } \\
\text { cellular fibrous tissue in the arterioles and small muscular arteries. } \\
\text { Large elastic arteries show atherosclerosis. }\end{array}$ \\
\hline & ually Irreversible \\
\hline 4 & $\begin{array}{l}\text { Progressive dilatation of the small arteries with plexiform lesions and } \\
\text { muscle hypertrophy is less apparent. }\end{array}$ \\
\hline 5 & $\begin{array}{l}\text { Chronic dilatation of the small arteries with plexiform and } \\
\text { angiomatoid lesions. }\end{array}$ \\
\hline 6 & Necrotizing arteritis with thrombosis. \\
\hline
\end{tabular}

(Heath D et al., Circulation 1958, 18: 533-547)

\section{Alterations of the pulmonary hemodynamics during the course of the disease according with Heath-Edwards classification: lessons from the "Sugen/Hypoxia" animal model of pulmonary hypertension}

It has been reported that in a rat model of severe PAH plexiform-like lesions $[8,10]$, characteristic of advanced PAH, develop [11]. This model (the Sugen/Hypoxia model) is based on a single percutaneous injection in rats of a vascular endothelial growth factor receptor blocker (SUGEN5416) which is combined with chronic exposure to hypoxia for three weeks. As classical rodent models of mild to moderate pulmonary hypertension $(\mathrm{PH})$, the chronic hypoxia and monocrotaline models have been used to investigate the mechanistic basis for the development of $\mathrm{PH}$ [12]. However, they lack phenotypically altered proliferated endothelial cells (ECs) in the lumen of pulmonary arteries and their defining pulmonary vascular remodeling was medial muscular thickening of proliferating smooth muscle cells (SMC) [13]. Therefore, there has been no obvious report focusing on the Heath-Edwards classification in these rodent models. On the other hand, in this model, not only plexiform-like lesions, but also all the pulmonary vascular abnormalities described in the Heath-Edwards classification, develop in a timedependent manner. Importantly there is also a linear correlation between the right ventricular (RV) systolic pressure (RVSP) and the number of obliterated vessels [14]. Remarkably, although the rats in this model develop severe PAH at five weeks after the SUGEN5416 injection, only grade 1 and 2 lesions of the Heath-Edwards classification were identified at this time point. This suggests that the severely elevated pulmonary arterial pressure observed in this rat model is due to these grade 1 and 2 lesions and/or the vascular tone increase in the early stage of the disease. The intimal occlusive lesions gradually progress in this rat model while the degree of medial thickness is decreasing [15]. These results suggest that a Heath-Edwards grade greater than 2, i.e., intimal lesions rather than medial lesions, appear to be mainly responsible for the increased pulmonary arterial blood pressure and the increased pulmonary arterial resistance (PVR) during the later stages of the disease. More recently de Raaf et al. used telemetry to monitor the time course of the increase in the RVSP [9] and found a reversible hypoxic vasoconstriction component in the Sugen/Hypoxia model and progressive intima remodeling and a media muscularization that was in proportion to the chronic hypoxia challenge.

The authors postulated that the hemodynamic and histological progression in this model are linked, however it has been critically acknowledged that animal models may not fully develop the complete spectrum of human histopathology, particularly when it comes to the 
time-dependence of the vascular changes [16]. The Sugen/Hypoxia rats are kept in a hypoxic chamber for the first three weeks of the protocol, indicating that chronic hypoxic pulmonary vasoconstriction (HPV) [17] likely induces high shear stress [18] and increased generation and secretion of growth factors and inflammatory cytokines within and around the pulmonary vasculature. This is associated with the appearance of smooth musclelike cells [19]. In human diseases, however, prolonged alveolar hypoxia likely occurs only in highlanders with $\mathrm{PH}[20]$ and regionally in patients with respiratory disease, including chronic obstructive pulmonary disease (COPD) and pulmonary fibrosis [21]. Taking this fact into account, the chronic hypoxia PAH model cannot reproduce the complete human pathobiology. In human forms of severe PAH phenotypically altered endothelial cells (ECs) [22, 23], uncontrolled cell proliferation [18, 24], inflammation $[25,26]$ and factors which can cause vasoconstriction or vasodilation [27-29], all appear to have a role in increasing the pulmonary vascular resistance.

\section{Sequential vascular remodeling according to the Heath-Edwards classification in human PAH}

Stacher and coworkers recently performed a detailed analysis of the histopathology of explanted lung samples obtained from 62 PAH patients and 28 control subjects in order to investigate the potential effects of modern therapy (prostacyclin and its analogs, phosphodiesterase type 5 inhibitors and endothelin receptor blockers) on the histopathological features observed in these patients. The authors demonstrated that a considerable number of the explanted lung samples from patients with endstage $\mathrm{PAH}$, who had been treated with modern PAH therapy, exhibited medial thickening that overlapped with the degree of media thickening found in the control lungs. On the other hand, they had a similar number of plexiform lesions as patients with other forms of progressive PAH [1]. Of the PAH patients 48 were characterized as a group with an IPAH-like pattern, which included 27 patients with IPAH, 9 patients with CHD-PAH, 5 patients with familial PAH, 3 patients with drug-related $\mathrm{PAH}, 2$ patients with venoocclusive disease, 1 patient with collagen vascular disease-PAH, and 1 patient with chronic thromboembolic pulmonary hypertension. There were no significant differences in the morphometric measurements or the plexiform lesions between the subgroups.

One particularly important result derived from the morphometric analysis of the PAH lesions in this study [1] is that sequential alterations in pulmonary vascular remodeling, as proposed by Heath and Edwards, may not be present (or may not occur) in PAH patients treated with modern therapy. The authors found plexiform lesions in the IPAH and associated PAH patients in spite of unimpressive medial remodeling. A subset of the explanted lung samples obtained from PAH patients with a progressive stage of disease had rather unremarkable medial lesions [1]. This fact supports the finding that Heath-Edwards classification grades 2 and/or 3 are likely responsible for the increased pulmonary arterial blood pressure in the Sugen/Hypoxia model [15]. At the time of lung transplantation, the intimal lesions with phenotypically altered mesenchymal-like cells [18, 22, 28, 29], including plexiform lesions, rather than medial remodeling, appeared to determine the elevated Ppa. However, there was no correlation between the number of plexiform lesions and the pulmonary hemodynamic values $[1,30]$ and there was only a tendency for a correlation between the intima plus media fractional thickness and hemodynamic values [1]. Thus, taken together, this suggests that, if the degree of occluded and stenosed pulmonary arterioles may determine the hemodynamics in patients with advanced $\mathrm{PAH}$, similar to the Sugen/Hypoxia model where there is a strong correlation between the RVSP and vessel lumen obliteration [14], the degree of these vascular remodeling may not be accurately assessed by either the intimal fractional thickness, the intimal volume density or the number of plexiform lesions.

Alternatively, or additionally still to be identified vasoconstrictive substances may contribute to the increased $P$ pa, even in end stage patients prior to lung transplantation [14]. However, at this stage a thinned and fibrosed media of the muscular arteries and arterioles appears [6], making it less likely that severe vasoconstriction dominates the picture.

If vasoconstriction is prominent, as it must be in those patients who are treatable with calcium channel blockers, it is of interest that these patients do not progress. We postulate that there is likely no pulmonary angioobliteration. However, histopathological studies of these patients' lungs are lacking.

\section{Determinants of the elevated pulmonary arterial pressure}

Almost five decades ago, the high pulmonary blood pressure associated with Heath-Edwards classification grades 1-3 was shown to be reversible following surgery that primarily eliminated the left to right shunt in $\mathrm{PAH}$ patients with CHD. However, $\mathrm{PH}$ associated with Heath-Edwards classification grade 4 was not reversible, at least acutely, after surgery [31]. These differences between grade 3 and 4 are due to the presence of complex intimal lesions that are composed of phenotypically altered mesenchymal-like cells $[18,22,28,29]$, indicating that the determinants of a fixed high pulmonary arterial pressure include complex vascular lesions, but not necessarily a high pulmonary blood flow. Oka et al. investigated the Sugen/Hypoxia rat model and found that pulmonary 
vascular tone remained to be an important contributing factor to the high $P_{\mathrm{pa}}$ even in the late stages of the disease. The role of increased vascular tone, in particular during exercise and perhaps also controlled by diurnal rhythms, may be underestimated in patients with fully developed angioobliterative disease [14] (Fig. 1). As the disease further progresses, a decrease in the cardiac output due to right ventricle dysfunction and failure results in a drop in $P_{\text {pa }}$ while the pulmonary vascular disease is ongoing.

In the Sugen/Hypoxia model, the extent of medial thickness decreases gradually as the disease progresses, while the high pulmonary arterial pressure is maintained [15]. Thus, this finding in the animal model resembles the data reported by Stacher et al. These authors showed in their study that approximately $75 \%$ of the lungs in patients with advanced PAH exhibited a medial fractional thickness which was similar to that in the controls, while 6/28 control lungs had an apparent medial fractional thickening not associated with plexiform lesions or $\mathrm{PH}[1]$. As a reminder, in rodent models of $\mathrm{PH}$ induced by chronic hypoxia or monocrotaline injection, the medial remodeling and elevated pulmonary arterial pressure are potentially reversible [13].

Thus, we wonder whether medial remodeling is indeed the critical factor responsible for the increase in the pulmonary arterial pressure, or whether the medial wall thickening is to some degree an adaptation of the vasculature to intermittently higher shear stress. It has been suggested that $\mathrm{PH}$ alters the smooth muscle cells' (SMCs) fiber length in order to maintain the transmural pulmonary arterial pressure as part of the pressure-adapting action of the pulmonary vasculature [32]. However, in human idiopathic PAH, the pulmonary arterial SMCs isolated from these patients showed dysfunctional voltage-sensitive potassium channels, which participate in pulmonary vascular tone control $[33,34]$. It is therefore likely that these patients' thickened pulmonary media layers, which are composed of functionally altered SMCs, have a direct role in increasing the pulmonary arterial pressure and that the degree of medial wall thickening is closely related to the vasoconstrictive potential [30].

Thus, it is likely that both medial and intimal wall remodeling contribute to the increase in pulmonary arterial pressure, as does adventitial remodeling due to proliferating fibroblasts [35] and deposition of extracellular matrix (ECM) in the pulmonary arteries [36]. Yet the degree of vasoconstriction may be limited in vessels altered by adventitial remodeling and in luminal stenosis (Fig. 1).

\section{Are there therapeutic strategies that are effective during different disease stages?}

The elevated pulmonary arterial pressure appears to be driven not only by the vascular tone, but also by the phenotypically altered proliferating cells [24]. The

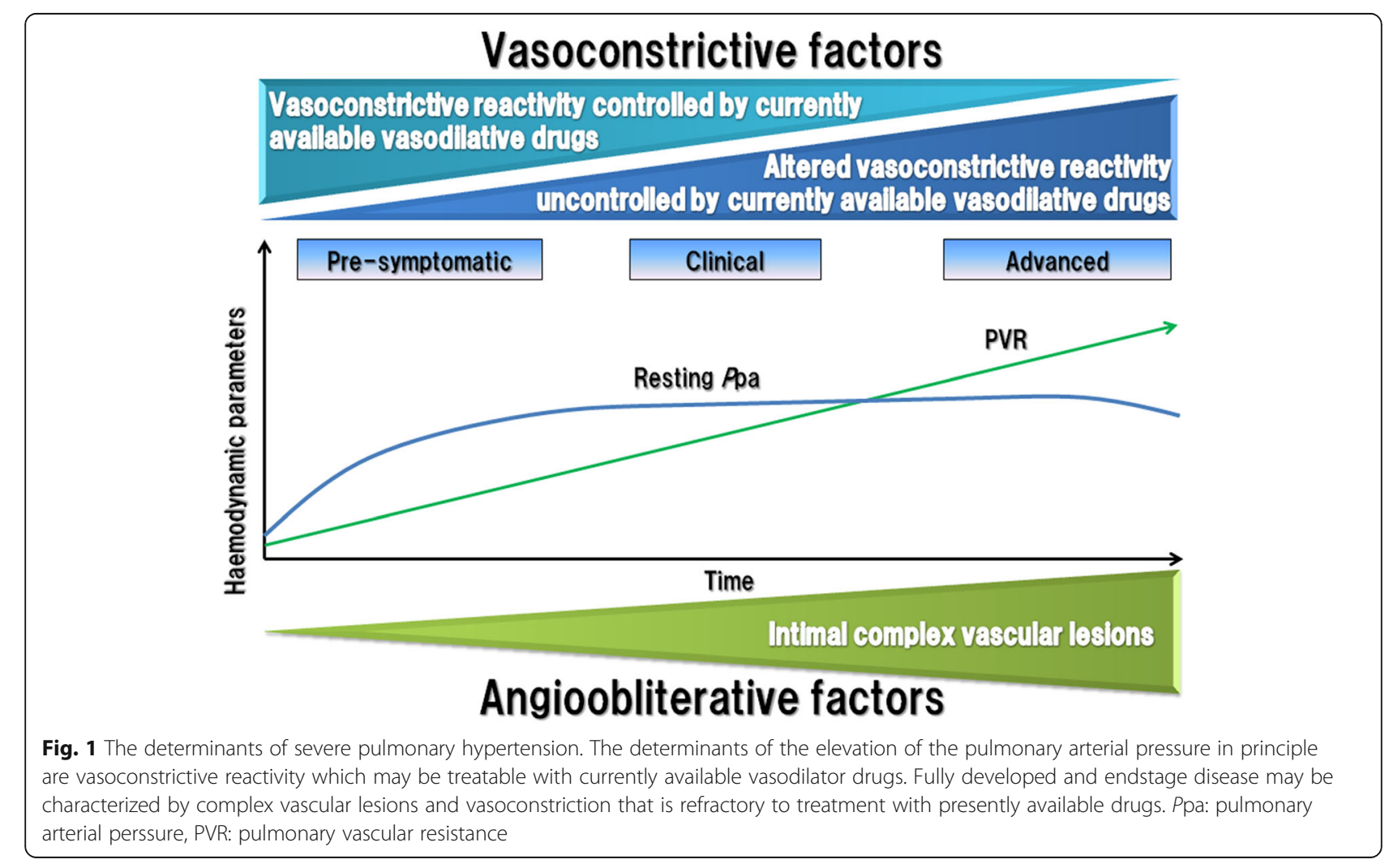


currently available $\mathrm{PH}$-targeted drugs including prostacyclin and its analogs, phosphodiesterase type 5 inhibitors and endothelin receptor blockers play a role both in opposing any abnormal vasoconstriction and in inhibiting the growth of SMC [37]. Despite therapy targeting $\mathrm{PH}$, more than $30 \%$ of $\mathrm{PAH}$ patients die within five years of receiving the diagnosis of severe $\mathrm{PAH}[38,39]$. The complex pulmonary vascular lesions remaining in the explanted lung tissue samples obtained from drug- treated PAH patients $[1,40]$ illustrate that the presently available drugs are not impacting the root causes of pulmonary vascular remodeling. Very differently, these drugs are effective in treating the $\mathrm{PH}$ in the monocrotaline rat model [41-44], which is characterized by medial thickening of the pulmonary arteries and muscularization of the pulmonary arterioles and the lack of intimal complex vascular lesions, including plexiform lesions [13]. This is likely attributable to the prominent role of pulmonary vasoconstriction in this monocrotaline model.

Early diagnosis is conceivably possible in certain forms of associated PAH (for example in patients with scleroderma, HIV/AIDS and sickle cell disease), however, it is unknown whether early disease stages in these patients cohorts are dominated by vasoconstriction. Indeed in patients with systemic sclerosis-associated $\mathrm{PAH}$, the vascular stiffness caused by luminal stenosis with fibrous alterations and medial thickening of arterioles are prominent histopathological findings throughout almost all scleroderma disease stages [7]. This implies that early therapeutic interventions with vasodilator drugs may not impact the vascular lesions in the PAH patients with connective tissue disease.

Drugs which can de-remodel the severely altered and often occluded vessels and novel vasodilators which can cause vasodilation when the current vasodilator drugs are not effective are needed for the treatment of patients with severe PAH.

\section{Conclusion}

Longitudinal studies of the Sugen/Hypoxia rat model of severe $\mathrm{PAH}$ have identified early and late disease stages $[8,9,14,15]$ and recent histopathological studies of lung explant tissues from patients treated with $\mathrm{PH}$-targeting drugs have found only a tendency towards a correlation between the hemodynamic values and the variably represented pulmonary vascular lesions [1]. Figure 1 presents the hypothesis that in many, or in some, patients there may be a presymptomatic, initial disease stage where pulmonary vasoconstriction may be treatable with currently available drugs. However, it is not a foregone conclusion that early vasodilation treatment would prevent the progression to vasoobliterative disease. The mechanistic details of the interplay between hemodynamic pulmonary vascular stress, initial vascular cell apoptosis, subsequent exuberant cell growth and pulmonary arteriolar lumen obliteration remain elusive $[24,45]$.

\section{Abbreviations}

PAH: Pulmonary arterial hypertension; IPAH: Idiopathic pulmonary arterial hypertension; Ppa: The mean pulmonary arterial pressure; CHD: Congenital heart disease; SUGEN5416: A vascular endothelial growth factor receptor blocker; RVSP: The right ventricular systolic pressure; PVR: Pulmonary arterial resistance; HPV: Hypoxic pulmonary vasoconstriction; COPD: Chronic obstructive pulmonary disease; ECs: Endothelial cells; PH: Pulmonary hypertension; SMCs: Smooth muscle cells; ECM: Extracellular matrix; HIV/AIDS: Human immunodeficiency virus/ acquired immunodeficiency syndrome

\section{Competing interests}

Dr. Sakao has received honoraria for lectures from Nippon Shinyaku Co., Ltd and Pfizer. Dr. Tanabe belongs to the endowed department sponsored by Actelion Pharmaceuticals, has received honoraria for lectures from Actelion, GlaxoSmithKline, Astellas and Pfizer.

Dr. Voelkel does not have a financial relationship with a commercial entity that has an interest in the subject of this manuscript. Dr. Tatsumi has received honoraria for lectures from Glaxo Smith Kline and Actelion Pharmaceutical Ltd and research grant support from Fukuda Denshi Co., Ltd. and Teijin Limited Teijin Ltd.

\section{Authors' contributions}

SS conceived of the report, contributed to the design and conception and drafted the manuscript. NFV, NT and KT drafted the manuscript and contributed to the design and conception. All authors read and approved the final manuscript.

\section{Funding}

This study was supported by research grants from the Respiratory Failure Research Group and Research on Intractable Diseases (24-57) from the Ministry of Health, Labour and Welfare, Japan, and the Grant-in-Aid for Scientific Research (JSPS KAKENHI Grant Number 15 K09210) from the Japanese Ministry of Education and Science.

\section{Author details}

'Department of Respirology (B2), Graduate School of Medicine, Chiba University, 1-8-1 Inohana, Chuo-ku, Chiba 260-8670, Japan. ${ }^{2}$ Victoria Johnson Center for Obstructive Lung Diseases and Pulmonary and Critical Care Medicine Division, Virginia Commonwealth University, Molecular Medicine and Research Building, Richmond, VA 23298-0456, USA.

Received: 16 December 2014 Accepted: 1 July 2015

Published online: 08 July 2015

References

1. Stacher E, Graham BB, Hunt JM, Gandjeva A, Groshong SD, McLaughlin W, et al. Modern age pathology of pulmonary arterial hypertension. Am J Respir Crit Care Med. 2012;186:261-72.

2. Howard LS. Prognostic factors in pulmonary arterial hypertension: assessing the course of the disease. Eur Respir Rev. 2011;20:236-42.

3. Rich S, Dantzker DR, Ayres SM, Bergofsky EH, Brundage BH, Detre KM, et al. Primary pulmonary hypertension: a national prospective study. Ann Intern Med. 1987;107:216-23.

4. Rich S. Primary pulmonary hypertension. Prog Cardiovasc Dis. 1988;31:205-38.

5. Brown LM, Chen H, Halpern S, Taichman D, McGoon MD, Farber HW, et al. Delay in recognition of pulmonary arterial hypertension: factors identified from the REVEAL Registry. Chest. 2011;140:19-26.

6. Heath D, Edwards JE. The pathology of hypertensive pulmonary vascular disease; a description of six grades of structural changes in the pulmonary arteries with special reference to congenital cardiac septal defects. Circulation. 1958;18:533-47.

7. Launay D, Sitbon O, Hachulla E, Mouthon L, Gressin V, Rottat L, et al. Survival in systemic sclerosis-associated pulmonary arterial hypertension in the modern management era. Ann Rheum Dis. 2013;72:1940-76.

8. Abe K, Toba M, Alzoubi A, Ito M, Fagan KA, Cool CD, et al. Formation of plexiform lesions in experimental severe pulmonary arterial hypertension. Circulation. 2010;121:2747-54 
9. de Raaf MA, Schalij I, Gomez-Arroyo J, Rol N, Happé C, de Man FS, et al. SuHx rat model: partly reversible pulmonary hypertension and progressive intima obstruction. Eur Respir J. 2014;44:160-8.

10. Taraseviciene-Stewart L, Kasahara Y, Alger L, Hirth P, Mc Mahon G Waltenberger J, et al. Inhibition of the VEGF receptor 2 combined with chronic hypoxia causes cell death-dependent pulmonary endothelial cell proliferation and severe pulmonary hypertension. FASEB J. 2001;15:427-38.

11. Eddahibi S, Morrell N, d'Ortho MP, Naeije R, Adnot S. Pathobiology of pulmonary arterial hypertension. Eur Resp J. 2002;20:1559-72.

12. Stenmark KR, Meyrick B, Galie N, Mooi WJ, McMurtry IF. Animal models of pulmonary arterial hypertension: the hope for etiological discovery and pharmacological cure. Am J Physiol Lung Cell Mol Physiol. 2009;297:L1013-1032.

13. Sakao S, Tatsumi K, Voelkel NF. Reversible or irreversible remodeling in pulmonary arterial hypertension. Am J Respir Cell Mol Biol. 2010;43:629-34.

14. Oka M, Homma N, Taraseviciene-Stewart L, Morris KG, Kraskauskas D, Burns $\mathrm{N}$, et al. Rho kinase-mediated vasoconstriction is important in severe occlusive pulmonary arterial hypertension in rats. Circ Res. 2007;100:923-9.

15. Toba M, Alzoubi A, O'Neill KD, Gairhe S, Matsumoto Y, Oshima K, et al. Temporal hemodynamic and histological progression in Sugen5416 hypoxia/normoxia-exposed pulmonary arterial hypertensive rats. Am J Physiol Heart Circ Physiol. 2014;306:H243-250.

16. Tuder RM, Archer SL, Dorfmüller P, Erzurum SC, Guignabert C, Michelakis E, et al. Relevant issues in the pathology and pathobiology of pulmonary hypertension. J Am Coll Cardiol. 2013;62:D4-D12.

17. Marshall BE, Marshall C, Benumof J, Saidman LJ. Hypoxic pulmonary vasoconstriction in dogs: effects of lung segment size and oxygen tension. J Appl Physiol. 1981;51:1543-51.

18. Sakao S, Taraseviciene-Stewart L, Lee JD, Wood K, Cool CD, Voelkel NF. Initial apoptosis is followed by increased proliferation of apoptosis-resistant endothelial cells. FASEB J. 2005;19:1178-80.

19. Stenmark KR, Fagan KA, Frid MG. Hypoxia-induced pulmonary vascular remodeling: cellular and molecular mechanisms. Circ Res. 2006;99:675-91.

20. Heath D, Williams D, Rios-Dalenz J, Calderon M, Gosney J. Small pulmonary arterial vessels of Aymara indians from the bolivian Andes. Histopathology. 1990;16:565-71.

21. Weitzenblum A, Chaouat M, Canuet R, Kessler R. Pulmonary hypertension in chronic obstructive pulmonary disease and interstitial lung diseases. Semin Respir Crit Care Med. 2009:30:458-70.

22. Sakao S, Taraseviciene-Stewart L, Cool CD, Tada Y, Kasahara Y, Kurosu K, et al. VEGF-R blockade causes endothelial cell apoptosis, expansion of surviving CD341 precursor cells and transdifferentiation to smooth muscle-like and neuronal-like cells. FASEB J. 2007:21:3640-52.

23. Masri FA, Xu W, Comhair SA, Asosingh K, Koo M, Vasanji A, et al. Hyperproliferative apoptosis-resistant endothelial cells in idiopathic pulmonary arterial hypertension. Am J Physiol Lung Cell Mol Physiol. 2007;293:L548-54

24. Rai PR, Cool CD, King JAC, Stevens T, Burns N, Winn RA, et al. The cancer paradigm of severe pulmonary arterial hypertension. Am J Respir Crit Care Med. 2008;178:558-64.

25. Price LC, Wort SJ, Perros F, Dorfmüller P, Huertas A, Montani D, et al. Inflammation in pulmonary arterial hypertension. Chest. 2012;141:210-21.

26. Tamosiuniene R, Tian W, Dhillon G, Wang L, Sung YK, Gera L, et al. Regulatory $T$ cells limit vascular endothelial injury and prevent pulmonary hypertension. Circ Res. 2011;109:867-79.

27. Giaid A, Saleh D. Reduced expression of endothelial nitric oxide synthase in the lungs of patients with pulmonary hypertension. N Engl J Med. 1995;333:214-21.

28. Giaid A, Yanagisawa M, Langleben D, Michel RP, Levy R, Shennib H, et al. Expression of endothelin-1 in the lungs of patients with pulmonary hypertension. N Engl J Med. 1993;328:1732-9

29. Christman BW, McPherson CD, Newman JH, King GA, Bernard GR, Groves $B M$, et al. An imbalance between the excretion of thromboxane and prostacyclin metabolites in pulmonary hypertension. N Engl J Med. 1992;327:70-5.

30. Yamaki S, Wagenvoort CA. Comparison of primary plexogenic arteriopathy in adults and children. A morphometric study in 40 patients. Br Heart J. 1985;54:428-34.

31. Heath D, JR H, Burchell HB, Dushane JW, Kirklin JW, Edwards JE. Graded pulmonary vascular changes and hemodynamic findings in cases of atrial and ventricular septal defect and patent ductus arteriosus. Circulation. 1958;18:1155-66.

32. Bagshaw RJ, Cox RH. Pulmonary vascular response is dependent upon initial state of the vasculature. Anesthesiology. 1983;58:205-6.
33. Murray F, Patel HH, Suda RY, Zhang S, Thistlethwaite PA, Yuan JX, et al. Expression and activity of CAMP phosphodiesterase isoforms in pulmonary artery smooth muscle cells from patients with pulmonary hypertension: role for PDE1. Am J Physiol Lung Cell Mol Physiol. 2007:292:L294-303.

34. Archer SL, Huang JM, Hampl V, Nelson DP, Shultz PJ, Weir EK. Nitric oxide and CGMP cause vasorelaxation by activation of a charybdotoxinsensitive $K$ channel by cGMP-dependent protein kinase. Proc Natl Acad Sci USA. 1994;91:7583-7.

35. Tozzi CA, Christiansen DL, Poiani GJ, Riley DJ. Excess collagen in hypertensive pulmonary arteries decreases vascular distensibility. Am J Respir Crit Care Med. 1994;149:1317-26.

36. Santos S, Peinado VI, Ramírez J, Melgosa T, Roca J, Rodriguez-Roisin R, et al. Characterization of pulmonary vascular remodelling in smokers and patients with mild COPD. Eur Respir J. 2002;19:632-8.

37. Humbert M, Sitbon O, Simonneau G. Treatment of pulmonary arterial hypertension. N Engl J Med. 2004;351:1425-36.

38. Thenappan T, Shah SJ, Rich S, Gomberg-Maitland M. A USA-based registry for pulmonary arterial hypertension: 1982-2006. Eur Respir J. 2007;30:1103-10.

39. Benza RL, Miller DP, Barst RJ, Badesch DB, Frost AE, McGoon MD. An evaluation of long-term survival from time of diagnosis in pulmonary arterial hypertension from the REVEAL Registry. Chest. 2012;142:448-56.

40. Achcar RO, Yung GL, Saffer H, Cool CD, Voelkel NF, Yi ES. Morphologic changes in explanted lungs after prostacyclin therapy for pulmonary hypertension. Eur J Med Res. 2006;11:203-7.

41. Clozel M, Hess P, Rey M, Iglarz M, Binkert C, Qiu C. Bosentan, sildenafil, and their combination in the monocrotaline model of pulmonary hypertension in rats. Exp Biol Med (Maywood). 2006;231:967-73.

42. Cui B, Cheng YS, Dai DZ, Li N, Zhang TT, Dai Y. CPU0213, a non-selective ETA/ETB receptor antagonist, improves pulmonary arteriolar remodeling of monocrotaline-induced pulmonary hypertension in rats. Clin Exp Pharmacol Physiol. 2009;36:169-75.

43. Liu H, Liu ZY, Guan Q. Oral sildenafil prevents and reverses the development of pulmonary hypertension in monocrotaline-treated rats. Interact Cardiovasc Thorac Surg. 2007:6:608-13.

44. Obata H, Sakai Y, Ohnishi S, Takeshita S, Mori H, Kodama M, et al. Single injection of a sustained release prostacyclin analog improves pulmonary hypertension in rats. Am J Respir Crit Care Med. 2008;177:195-201.

45. Voelkel NF, Gomez-Arroyo J, Abbate A, Bogaard HJ, Nicolls MR. Pathobiology of pulmonary arterial hypertension and right ventricular failure. Eur Respir J. 2012;40:1555-65.

\section{Submit your next manuscript to BioMed Central and take full advantage of:}

- Convenient online submission

- Thorough peer review

- No space constraints or color figure charges

- Immediate publication on acceptance

- Inclusion in PubMed, CAS, Scopus and Google Scholar

- Research which is freely available for redistribution

Submit your manuscript at www.biomedcentral.com/submit 